\title{
INFÂNCIA, EXPERIÊNCIA E MEMÓRIA NA OBRA O DIA EM QUE NÃO VOLTEI A CASA, DE NGO NUNI ${ }^{1}$
}

Diana Navas

Evandro Fantoni Rodrigues Alves

Resumo: As ideias de Infância, Experiência e Memória são muito caras e estão muito presentes na Literatura, seja no âmbito da produção ficcional propriamente dita, seja no âmbito da crítica literária. O presente artigo visa estabelecer uma relação entre essas três ideias e a obra $O$ dia em que não voltei a casa, de Ngo Nuni. Para isso, apresentamos de forma sintética as formulações teóricas de Philippe Ariès, Neil Postman, Walter Benjamin, Giorgio Agamben, Perry Anderson e Jeane Marie Gagnebin para as ideias de Infância, Experiência e Memória, respectivamente bem como alguns dos principais fatos históricos acerca do Movimento pela Libertação de Cabinda, a partir das palavras de Eric Hobsbawn, Leila Leite Hernandez, e Eugênio Costa Almeida. A partir daí, procedemos à análise de algumas das narrativas apresentadas por Ngo Nuni em sua obra, procurando entender de que forma o cenário de guerra impactou em sua infância, e que tipo de experiências e memórias foram cristalizadas em $O$ dia em que não voltei a casa, uma obra que ao mesmo em que possui uma elevada qualidade estética, denuncia os incontáveis crimes cometidos contra o povo de Cabinda.

Palavras-chave: Literatura. Infância. Experiência. Memória. Angola. Cabinda. Biografia.

Abstract: The ideas of Childhood, Experience and Memory are very esteemed and are very present in Literature, whether in the scope of fictional production itself, or in the scope of literary criticism. This article aims to establish a relationship between these three ideas and Ngo Nuni's work $O$ dia em que não voltei a casa. For that, we present in a synthetic way the theoretical formulations of Philippe Ariès, Neil Postman, Walter Benjamin, Giorgio Agamben, Perry Anderson and Jeane Marie Gagnebin - for the ideas of Childhood, Experience and Memory, respectively - as well as some of the main historical facts about the

1 Título em língua estrangeira: “Childhood, experience and memory in $O$ dia em que não voltei a casa, from Ngo Nuni". 
Movement for the Liberation of Cabinda, based on the words of Eric Hobsbawn, Leila Leite Hernandez, and Eugênio Costa Almeida. From there, we proceeded to the analysis of some of the narratives presented by Ngo Nuni in his work, trying to understand how the war scenario had an impact on his childhood, and what kind of experiences and memories were crystallized in $O$ dia em que não voltei a casa, a work that has, at the sime time, a high aesthetic quality, and denounces the countless crimes committed against the people of Cabinda.

Keywords: Literature. Childhood. Experience. Memory. Angola. Cabinda. Biography.

\section{Introdução}

As ideias de Infância, Experiência e Memória são muito caras e estão muito presentes na Literatura, tanto no âmbito da produção ficcional propriamente dita, quanto no âmbito da Crítica Literária, e o presente artigo tem como objetivo refletir sobre ambas as instâncias, a partir do estabelecimento de relações entre essas três ideias e a obra O dia em que não voltei a casa, de Ngo Nuni. Para isso, ele se dividirá em três momentos.

No primeiro momento, intitulado "Infância: Experiência e Memória", apresentaremos de forma sintética os três conceitos, recorrendo às formulações teóricas de Philippe Arriès - em História social da criança e da família - e de Neil Postman - em $O$ desaparecimento da infância - acerca da ideia de "Infância", sua construção ao longo dos séculos e seu potencial desaparecimento no tempo presente, em 
decorrência de inúmeros fatores, dentre os quais a ideia de uma infância vivida em contexto de guerra, o que nos leva à segunda ideia fundamental do artigo.

Discutiremos brevemente a ideia de "Experiência" a partir das reflexões de Giorgio Agamben - em Infância e história - e de Walter Benjamin - em "Experiência e Pobreza" - ampliando suas formulações a respeito das consequências que o horror das guerras mundiais deixou em seus participantes para o contexto de guerra moderno, como a que ocorreu - e ainda ocorre - durante a infância de Ngo Nuni.

O debate entre as relações entre experiência e guerra nos levam quase que de forma automática à ideia de "Memória", enquanto construto teórico-filosófico acerca da necessidade de revisitar certos traumas a fim de melhor processá-los, e do recurso à memória - inclusive escrita, como o caso da obra $O$ dia em que não voltei a casa - para o processamento e a transmissão de experiências. Para tanto, recorreremos às palavras de Perry Anderson - em Trajetos de uma forma literária - e de Jeanne Marie Gagnebin - em Lembrar escrever esquecer.

No segundo momento, nos debruçaremos sobre o contexto histórico da guerra pela libertação de Cabinda, procurando entender os diferentes atos que compõe essa 
história, partindo dos movimentos pela independência de Angola, até os dias atuais, quando os membros do governo angolano negam ao povo cabinda o direito à sua própria liberdade e independência.

Para tanto, no que concerne ao Movimento pela Libertação de Angola (MPLA), e ao processo de independência do país africano, iniciado na década de 1960 e concluído em 1975, nos valeremos das palavras de Eric Hobsbawn - em A era dos extremos - de Leila Leite Hernandez - em A África na sala de aula.

Para os aspectos mais específicos da história cabinda, e de sua própria luta pela independência - encabeçada pela Frente pela Libertação do Enclave de Cabinda (FLEC) - nos valeremos tanto das palavras de Ngo Nuni, em sua obra literária, e de Eugênio Costa Almeida - em "O difícil processo de definição de fronteiras e pertenças político identitárias no debate de Cabinda".

O terceiro - e mais significativo - momento deste artigo é aquele em que se dará a análise de algumas das narrativas apresentadas por Ngo Nuni em sua obra, procurando entender através desses excertos - pois nos seria impossível fazer uma análise aprofundada da obra toda, em decorrência do espaço limitado de um artigo - de 
que forma(s) o cenário de guerra pela libertação de Cabinda impactou a infância do autor, e que tipo de experiências e memórias - e denúncias - foram cristalizadas em $O$ dia em que não voltei a casa.

\section{Infância: Experiência e Memória}

Ao tratarmos de conceitos tão amplos e complexos como os de "infância", "experiência" e "memória”, faz-se necessário estabelecer algumas diretrizes teóricas, para que melhor possamos proceder nosso estudo. E é a esse propósito que o primeiro item do presente artigo se destina, iniciando pela ideia de "infância".

A primeira medida que devemos tomar em relação à compreensão da ideia de "infância" é no sentido de entendermos que tal categoria etária é de construção histórica, ou seja, ela foi sendo estabelecida e transformada com o passar do tempo, e nem sempre esteve presente na sociedade humana, tendo sido primeiramente criada no período renascentista, e se cristalizado já no século XIX.

Neil Postman, em obra dedicada ao desaparecimento da infância na sociedade contemporânea - intitulado justamente $O$ desaparecimento da infância - nos informa que "das atitudes para com as crianças na antiguidade sabemos muito pouco. Os gregos, por exemplo, prestavam 
pouca atenção na infância como categoria etária especial" (1999, p. 19) e mais adiante nos diz que "no mundo medieval a criança é, numa palavra, invisível." (1999, p. 33). Barbara Tuchman (1978 apud POSTMAN, 1999) destaca ainda que "de todas as características que diferenciam a Idade Média da moderna, nenhuma é tão contundente quanto a falta de interesse pelas crianças". Postman segue essa mesma linha de pensamento de Tuchman, asseverando que

a idéia de infância é uma das grandes invenções da Renascença. Talvez a mais humanitária. Ao lado da ciência, do estadonação e da liberdade de religião, a infância, como estrutura social e como condição psicológica, surgiu por volta do século dezesseis e chegou refinada e fortalecida aos nossos dias. (POSTMAN, 1999, p. 12)

É importante observar, porém, que mesmo tendo surgido no período renascentista, a ideia de infância foi se desenvolvendo ao longo do tempo, agregando diferentes valores de diversas ordens - algumas delas relativamente distantes umas das outras - até que se cristalizasse no século XIX com a roupagem que entendemos como sendo o conceito tradicional de infância, ainda que ao longo do século XX já seja possível observarmos uma série de transformações.

Em sua obra dedicada ao tema da infância - História social da criança e da família - Philippe Ariès apresenta, 
na conclusão da primeira parte do livro, um resumo desse trajeto de desenvolvimento do conceito de infância, descrevendo os principais aspectos e valores agregados à ideia de infância, e os momentos históricos aproximados em que foram incorporados, até que a criança passasse a configurar-se como figura central da vida familiar.

O primeiro sentimento da infância caracterizado pela "paparicação" - surgiu no meio familiar, na companhia das criancinhas pequenas. O segundo, ao contrário, proveio de uma fonte exterior à família: dos eclesiásticos ou dos homens da lei, raros até o século $\mathrm{XVI}$, e de um maior número de moralistas no século XVII, preocupados com a disciplina e a racionalidade dos costumes. Esses moralistas haviam-se tornado sensíveis ao fenômeno outrora negligenciado da infância, mas recusavam-se a considerar as crianças como brinquedos encantadores, pois viam nelas frágeis criaturas de Deus que era preciso ao mesmo tempo preservar e disciplinar. Esse sentimento, por sua vez, passou para a vida familiar.

No século XVIII, encontramos na família esses dois elementos antigos associados a um elemento novo: a preocupação com a higiene e a saúde física. $O$ cuidado com o corpo não era desconhecido dos moralistas e dos educadores do século XVII. Tratava-se dos doentes com dedicação (e também com grandes precauções para desmascarar os simuladores), mas não havia interesse pelo corpo dos que gozavam de boa saúde, a não ser com um objetivo moral: um corpo mal 
enrijecido inclinava à moleza, à preguiça, à concupiscência, a todos os vícios.

A correspondência do General de Martange com sua mulher nos dá uma ideia das preocupações íntimas de uma família. [...] Martange nasceu em 1722 e casou-se em 1754. [...] Martange se preocupava com tudo o que dissesse respeito à vida de seus filhos, desde a "paparicação" até a educação. Havia também uma grande preocupação com sua saúde e até mesmo sua higiene. Tudo o que se referia às crianças e à família tornara-se um assunto sério e digno de atenção. Não apenas o futuro da criança, mas também sua simples presença e existência eram dignas de preocupação - a criança havia assumido um lugar central dentro da família. (ARIÉS, 1986, p. 163-164)

Tendo apresentado um brevíssimo panorama de como a ideia de infância têm se desenvolvido ao longo dos anos, podemos passar ao segundo momento do presente estudo, em que faremos algumas considerações acerca da ideia de "Experiência", conforme nos é apresentado, através de uma memória pessoal, pelo filósofo alemão Walter Benjamin, em seu ensaio "Experiência e pobreza".

Em nossos livros de leitura havia a parábola de um velho que, no leito de morte, revela a seus filhos a existência de um tesouro oculto em seus vinhedos. Bastava desenterra-lo. Os filhos cavam, mas não descobrem vestígio do tesouro. Com a chegada do outono, porém, as vinhas produzem mais que qualquer 
outra na região. Só então compreenderam que o pai lhes havia transmitido uma certa experiência. [...] Tais experiências nos foram transmitidas, de modo benevolente ou ameaçador, à medida que crescíamos [...] Sabia-se também exatamente o que era a experiência: ela sempre fora comunicada pelos mais velhos aos mais jovens. De forma concisa, com a autoridade da velhice, em provérbios; de forma prolixa, com sua loquacidade, em histórias; às vezes como narrativas de países longínquos, diante da lareira, contadas a filhos e netos. (BENJAMIN, 2012, p. 123)

Como podemos observar, a noção de "experiência" estaria - para Benjamin e para nosso estudo - ligada à ideia de transmissão de saberes aos mais jovens pelos mais velhos, através de uma grande miríade de recursos, que podem variar de cultura para cultura e de sociedade para sociedade.

É importante destacar também que a noção benjaminiana de "Experiência" estava dissociada da ideia contemporânea de ciência, ou seja, a experiência da qual nos fala Benjamin e que consideramos no presente artigo - se refere sim a um conhecimento prático, mas não controlado artificialmente, e sim em decorrência do vivido, conforme nos explica Giorgio Agamben em Infância e história: Destruição da experiência e origem da história.

A ideia de uma experiência separada do conhecimento tornou-se para nós tão 
estranha a ponto de esquecermos que, até o nascimento da ciência moderna, experiência e ciência possuíam cada uma o seu lugar próprio. E não só: distintos também eram os sujeitos de que lançavam mão. Sujeito da experiência era o senso comum, presente em cada indivíduo (é o <<princípio que julga〉> de Aristóteles e a vis estimativa da psicologia medieval, que não são ainda o que chamamos de bom senso), enquanto que o sujeito da ciência é o nous ou intelecto agente, que é separado da experiência <<impassível>> e $<$ divino >> (aliás, para sermos precisos, o conhecimento não possuía nem mesmo um sujeito no sentido moderno de um ego, mas, ao contrário, era o próprio indivíduo o sub-jectum no qual o intelecto agente, único e separado, realizava o conhecimento). (AGAMBEN, 2008, p. 26)

Esse conceito de experiência, porém, vai ser entendido tanto por Benjamin quanto por Agamben como algo que a humanidade não seria mais capaz de transmitir, em decorrência dos traumas ocasionados pela I Guerra Mundial, em primeiro lugar, e pelo próprio ritmo da sociedade contemporânea, que nos inunda de acontecimentos sem que nos ofereça de fato experiências que possam ser transmitidas. Uma vez mais recorremos às palavras de Benjamin:

Não, está claro que as ações da experiência estão em baixa, e isso numa geração que entre 1914 e 1918 viveu uma das mais terríveis experiências da história universal. Talvez isso não seja tão estranho como 
parece. Na época, já se podia notar que os combatentes voltavam silenciosos do campo de batalha. Mais pobres em experiências comunicáveis, e não mais ricos. Os livros de guerra que inundaram o mercado literário dez anos depois continham tudo menos experiências transmissíveis de boca a boca. (BENJAMIN, 2012, p. 123-124)

No final do excerto, observamos que o filósofo alemão refere-se aos livros de guerra surgidos com o final da conflagração mundial, afirmando que seu conteúdo não poderia ser veiculado de boca a boca - ou seja, de forma direta - como experiências obtidas pelos combatentes que sobreviveram ao conflito.

Essa noção de que as experiências de guerra - aqui expandindo a ideia trazida por Benjamin para qualquer contexto de guerra, e não nos limitando à primeira das duas mundiais - não poderia ser transmitida de boca a boca nos leva a refletir acerca da possibilidade ou não de transmissão dessas vivências, o que nos direciona para o próximo grande conceito histórico que nos será fundamental no presente trabalho: a ideia de "Memória".

A primeira coisa que gostaríamos de destacar é que não entendemos, no presente artigo, "Experiência" e "Memória" como conceitos totalmente dissociados. Diferentes, sim, porém próximos, uma vez que acreditamos 
que a "Memória", em suas limitações, de certa forma diz respeito às experiências vividas por um determinado indivíduo. Assim, a "Memória" pode ser entendida, entre outras coisas, como um recurso pelo qual se acessa o passado, e as "Experiências" nele vividas.

É importante destacar, porém, que apesar do que diz o senso comum - que lembrar é viver - ao acessarmos uma determinada memória a fim de revisitar determinadas experiências, nós não as revivemos, mas sim as acessamos conforme ela "relampeja no momento de perigo". Recorrermos novamente às palavras de Benjamin:

A verdadeira imagem do passado passa voando. O passado só se deixa capturar como imagem que relampeja irreversivelmente no momento de sua conhecibilidade. [...] Articular historicamente o passado não significa conhecê-lo "tal como ele de fato foi". Significa apropriar-se de uma recordação, como ela relampeja no momento de um perigo. (BENJAMIN, 2016, p. 243 , grifos do autor)

Tendo deixado claro esse posicionamento, podemos partir para uma observação mais aprofundada das relações que se estabelecem entre "Experiência" e "Memória", e de que maneira esses dois conceitos podem ser relacionados à ideia de "Infância". 
Em primeiro lugar, observamos que Benjamin afirma que certas experiências, por sua natureza tão violenta e traumática, não poderiam ser comunicadas de boca a boca. O autor menciona como exemplo maior desses eventos traumáticos a I Guerra Mundial, ocorrida entre 1914 e 1918. Por outro lado, o pensador alemão também assegura que os livros com relatos sobre a guerra inundaram as prateleiras, repletos de experiências que não poderiam ser verbalmente comunicadas.

Acreditamos que, mesmo sendo impossível transmitir certas experiências de boca a boca, ou através da experimentação - ninguém em sã consciência desejaria que um filho ou neto passasse pela experiência de uma guerra como a de 1914 para que conhecesse a profundidade dos seus horrores - é necessário que elas sejam transmitidas de alguma forma, para que os mesmos erros não sejam cometidos, e esse recurso seria, cremos, a literatura.

Cabe aqui nos questionar acerca da necessidade de transmitir essas vivências, ainda que através de experiências literárias, e não mais de experiências transmitidas oralmente, e acreditamos que é nesse ponto que os conceitos de "Experiência" e "Memória" se interseccionam. É necessária a transmissão de certas 
experiências - por mais traumáticas que sejam - para que elas não sejam esquecidas, ou seja, para que possam ser historicamente articuladas - como afirma Benjamin - em um momento de perigo.

A esse respeito, Jeanne-Marie Gagnebin - em Lembrar escrever esquecer - nos informa da importância e do papel da "Memória" enquanto experiência coletiva humana, ou seja, como um recurso válido para se evitar que as mesmas atrocidades verbalmente incomunicáveis se repitam, por vezes em proporções até maiores. Para tanto, ela se vale de um exemplo bastante intenso, que fala por si.

Querendo aniquilar um povo inteiro, a "solução final" pretendia também destruir toda uma face da história e da memória. Essa capacidade de destruição da memória cobre uma dimensão política e ética a respeito da qual Hitler estava perfeitamente consciente. [...] "Eu dei ordem às unidades especiais da SS de se apoderarem do fronte polonês e de matarem sem piedade homens, mulheres e crianças. Quem ainda fala dos extermínios dos armênios, hoje?", declara ele em 21 de agosto de 1939. (GAGNEBIN, 2014, p. 47)

O massacre armênio, ao qual Hitler se refere, ocorreu em 1915, durante o contexto da I Guerra Mundial, e que já em 1939 - e ainda hoje, a não ser em grupos culturais armênios ou a eles ligados - era muito pouco falado ou denunciado de forma geral. Durante esse evento, o governo totalitário 
liderado pelo partido Jovens Turcos realizou um massacre étnico em suas fronteiras, causando a morte de mais de um milhão e meio de armênios inocentes, sem que sofressem nenhum tipo de sanção.

A bem da verdade, até hoje o governo turco não admite que se use o termo genocídio acerca do evento, afirmando que o que ocorreu foi, sim, uma atrocidade no sentido de deportar mais de um milhão de armênios para o deserto da Síria, mas afirma que não houve tentativa sistemática de extermínio dessa população.

É justamente esse tipo de silêncio que a transmissão de certas experiências traumáticas visa evitar, ou seja, que certos eventos sejam historicamente ignorados, permitindo que pessoas mal-intencionadas os reproduzam, ou promovam outros de cunho semelhante.

Dentro desse contexto, podemos nos perguntar onde entra a "Infância", e ela permeia tanto as noções de "Experiência" como as de "Memória", especialmente no que concerne ao texto estudado no presente artigo, uma vez que os anos de formação do autor Ngo Nuni foram profundamente rasgados e marcados pelo contexto de guerra em seu país, fazendo com que ele, em tenra idade, experimentasse o mesmo tipo de experiência 
vivida - guardadas as devidas proporções em termos de temporalidade e contexto - pelos jovens enviados aos campos de batalha da I Guerra Mundial.

Esse contexto de guerra faz com que o autor - segundo nos informa em sua obra, conforme veremos mais adiante tenha tido recebido de seus pais e familiares mais velhos não apenas experiências de vida e de aprendizado, mas também tenha vivenciado traumas verbalmente incomunicáveis, mas necessários de transmissão, para que o massacre do povo cabindense por certas autoridades angolanas não caia no esquecimento, como o mencionado massacre armênio.

Antes, porém, de nos aprofundarmos nos relatos experiências e memórias - da ainda em curso Guerra pela Libertação de Cabinda, consideramos de fundamental importância apresentar, ainda que brevemente, o contexto histórico no qual Ngo Nuni viveu a sua infância, e ao qual se refere em $O$ dia em que não voltei a casa.

\section{Cabinda: uma História de lutas}

A obra O dia em que não voltei a casa, de Ngo Nuni, relata diferentes episódios da vida e infância do autor no contexto da guerra pela libertação de Cabinda, intensificada com o reconhecimento - por parte do governo português - da independência de Angola, no ano de 1975. 
Antes de nos debruçarmos diretamente nos episódios narrados por Ngo Nuni em seu livro, consideramos importante revisitar o contexto histórico ao qual o autor se refere em sua obra, ou seja, o cenário em que se encontrava o enclave de Cabinda quando da ocorrência dos eventos narrados. Procuraremos fazer isso brevemente, iniciando pelo processo de independência de Angola de forma mais ampla, para depois nos concentrarmos no caso específico de Cabinda.

Seria um grave erro histórico afirmar que os movimentos pela libertação de Angola surgiram no século XX. Muito pelo contrário, o povo angolano sempre - em maior ou menor grau - ofereceu resistência ao domínio português, mas, para fins deste estudo, e diante da impossibilidade de uma apresentação detalhada de toda essa história de lutas, escolhemos o recorte do século XX pra tratarmos da independência angolana.

Nesse contexto, é possível afirmar que os primeiros movimentos amplos de contestação da ordem estabelecida pelo governo português se deram a partir do final da Segunda Guerra Mundial, quando se formaram diferentes associações - majoritariamente lideradas por crioulos - que começavam a ensaiar um posicionamento 
contra o colonialismo de Portugal, conforme nos informa Leila Leite Hernandez, em A África na sala de aula. Visita à história contemporânea.

Em Angola foram os crioulos, uma elite cultural surgida no pós-1945, que apresentaram uma capacidade inconteste para mobilizar a grande maioria rural em torno de uma luta capaz de ultrapassar o reformismo. Mais ampla e coesa [...] essa luta foi ganhando uma perspectiva nacional e revolucionária, cujo marco inicial foi 1947, quando o Grêmio Africano passou a chamarse Associação dos Naturais de Angola (Anangola). [...] Embora com muitos e graves problemas de organização, estudantes crioulos e, em menor número, brancos e negros usavam as associações culturais ou recreativas, iniciando um tímido processo de contestação aos aspectos do sistema colonial. (HERNANDEZ, 2008, p. 573)

Com o passar dos anos, foram criando-se uma série de outros movimentos cujo objetivo era lutar pela independência angolana em relação à Portugal, sendo que muitos deles tinham, inclusive, um caráter regionalista - muitas vezes tipificado como tribal por grupos que não entendiam, ou se recusavam a entender, a dinâmica dos diferentes povos que compunham as posses portuguesas em África - que acabou fazendo com que não se unissem com outros movimentos, por incompatibilidade de ideais, posto que vários desses 
grupos - como é o caso dos movimentos ela libertação de Cabinda, que veremos mais adiante - visavam não apenas a independência em relação a Portugal, mas também uma emancipação em relação à própria Angola.

Dentre os grupos que mais obtiveram adesões, e que por isso se tornaram os mais importantes e com maior poder de enfrentamento aos portugueses, podemos destacar três, sendo que o primeiro deles, o Movimento Pela Libertação de Angola (MPLA), havia se formado pela junção de grupos de militantes do Partido Comunista de Angola com o Partido da Luta Unida dos Africanos de Angola (PLUA).

De acordo com a versão oficial do MPLA, este partido foi fundado em 10 de dezembro de 1956 e resultava da junção do Plua com outros militantes fundadores do PC de Angola. Nesse momento destacaramse Mário Pinto de Andrade, Agostinho Neto e Viriato Cruz, que professavam a "ideologia marxista". Quanto à base de apoio do MPLA, foi, na sua maior parte, constituída por operários de Luanda e de outras cidades em expansão, mais ao sul, como Benguela e Huambo, contando com um significativo apoio dos quimbundos. (HERNANDEZ, 2008, p. 574)

O segundo desses grupos que ganharam destaque nos movimentos emancipatórios angolanos foi a União das Populações ao Norte de Angola (UPA), que apesar 
de ter obtido certo destaque e importância no processo independentista, tinha um caráter regionalista, buscando essencialmente - com o apoio de missionários religiosos britânicos e norte-americanos - o reestabelecimento do antigo Reino do Congo, origem da etnia majoritária da UPA.

No que se refere à UPA, estava ligada aos emigrantes angolanos sediados no então Congo Belga. Eram operários, na sua maior parte, unidos por associações semi-secretas de raiz bakongo. Em 1954 fundaram a União das Populações ao Norte de Angola (UPA), liderada por Holden Roberto e que, mais tarde, passou a chamar-se Frente Nacional de Libertação de Angola (FNLA). É preciso lembrar que este foi um movimento de bakongos que ansiavam por conquistar a autonomia do seu próprio território, projeto reforçado pelas missões religiosas britânicas e norte-americanas com o objetivo de restaurar o "reino" do Congo. (HERNANDEZ, 2008, p. 575)

Por fim, o terceiro grupo que mais destacou-se no processo de independência de Angola foi a União Nacional para Independência Total de Angola (UNITA), que surgiu no ano de 1966, a partir de cisões da FNLA, e sob a liderança de Jonas Savimbi, com apoio especial dos povos ovimbundos.

Anos depois, com a cisão da Frente, surgiu, em 1966, a União Nacional para a Independência Total de Angola (Unita), apoiada sobretudo pelos ovimbundos 
e liderada por Jonas Savimbi, que havia obtido há pouco tempo o seu doutorado em ciência política, em Genebra. (HERNANDEZ, 2008, p. 576)

Mesmo com o aparecimento de alguns movimentos mais fortes e "nacionais" e de incontáveis outros de caráter mais étnico e regional, o governo colonial português se recusava a negociar com os angolanos acerca de sua independência, o que ocasionou uma série de protestos e revoltas, duramente reprimidos por Portugal.

Essa posição intransigente - mesmo depois de começar a sofrer pressões internacionais - dos portugueses, aliado com o exemplo dado por outros tantos países africanos em seu processo de emancipação, levou os diferentes grupos a adotarem posições mais radicais, partindo para a luta armada e a guerrilha, uma vez que não acreditavam mais ser possível chegarem a lugar nenhum se esperassem uma transição pacífica por parte do governo português.

Os conflitos entre as guerrilhas e o governo português se estenderam por anos, até pelo menos o ano de 1974, com incontável prejuízo sobretudo para as populações civis, que se viam no meio do fogo cruzado entre os grupos beligerantes. É importante lembrar ainda que os diferentes grupos que lutaram pela libertação angolana não agiram em conjunto, e que o governo português negociou com cada 
um deles, separadamente, tratados de cessar fogo, ao final dos quais - e de um governo de transição - o MPLA obteve o reconhecimento pelos portugueses da independência angolana, assumindo o governo do país africano, conforme nos informa Hernandez.

[...] os movimentos de independência continuaram a atuar separadamente: o MPLA em Cabinda, a FNLA ao norte de Angola e a Unita a leste. Além disso, cada qual assinou um cessar fogo com os portugueses [...] Do final de 1974 a novembro de 1975 teve lugar um governo de transição, também chamado de conciliação, segundo o Acordo de Alvor, firmado entre o governo português (que tomou o poder em Portugal com a Revolução dos Cravos), o MPLA, a FNLA, e a Unita. Depois do período de transição, em 11 de novembro de 1975 o MPLA, sob a direção de Agostinho Neto, proclamou a independência, reconhecida pelo governo português. (HERNANDEZ, 2008, p. 580)

Antes de passarmos a tratar da questão de Cabinda de forma mais direta - que o que mais fortemente nos interessa -, é importante destacar que, conforme nos informa Hernandez, apesar de um discurso unitário e um programa de governo libertário, o MPLA não colocou em prática os próprios princípios por eles defendidos.

O programa completava-se com a escolha de instalar em Angola um regime republicano, democrático, laico e baseado no sufrágio 
universal. Também propunha um Estado "forte", isto é, centralizados e concentrador de poder, tendo sob sua direção as empresas dos setores básicos da economia. Além disso, tinha o propósito de realizar uma reforma agrária. Faz-se necessário acrescentar que, embora o MPLA fosse, em essência, um movimento de mestiços e com dificuldades para compreender o caráter específico das culturas dos povos africanos em Angola, não conquistou o apoio de vários grupos da população. Em outros termos: ao mesmo tempo que em seus projetos culturais ressaltava o respeito pelas diversas identidades, por diferentes razões, pragmaticamente, sua ação contrariava o discurso corrente. (HERNANDEZ, 2008, p. 578)

O reconhecimento da independência de Angola, contudo, não significou o fim dos conflitos na região de Cabinda, um enclave ao norte do país, que com ele não faz nenhuma fronteira física, pois situa-se entre a República do Congo e a República Democrática do Congo. Ao contrário do que movimentos independentistas de Cabinda almejavam desde os primeiros atos contra Portugal, a sua própria independência em relação a Angola não foi reconhecida pelo governo chefiado pelo MPLA, muito em decorrência de suas características físicas que ofereciam grande potencial de exploração econômica, tanto de sua floresta do Mayombe, como da possibilidade de pesca em sua faixa oceânica, e mais ainda - um pouco mais tarde - das grandes 
reservas petrolíferas da região, conforme nos informa Eugênio Costa Almeida, em seu artigo "O difícil processo de definição de fronteiras e pertenças político-identitárias no debate de Cabinda":

Situada a 50 quilômetros ao norte da foz do rio Zaire, a província [de Cabinda] está "encravada geograficamente entre os dois Congos. [...] Não tem, por isso, qualquer fronteira física com a República angolana. Apesar do seu limitado espaço territorial, Cabinda tem uma costa expressiva [...] que se revelou, para o bem e para o mal, mais um empecilho nas jogadas estratégicas das potências coloniais. À época, da exploração colonial, tal como ainda hoje, as potencialidades da sua floresta do Maiombe também emergiram como um motivo de avidez.

E se, até 1961, a realidade em matéria de potencialidades econômicas do pequeno território estava na floresta e na pesca, por volta de 1964 (três anos após o início da guerra independentista em Angola), quando se deu início à exploração da enorme capacidade petrolífera de Cabinda, o cenário alterou-se, colocando o território na primeira linha dos interesses estratégicos regionais e mundiais. (ALMEIDA, 2013, p. 68)

Como é facilmente perceptível, existe um profundo interesse econômico da parte do governo angolano e português antes dele - nos recursos naturais que o território de Cabinda oferece, e são justamente essas 
questões econômicas que geram tantos entraves no processo de reconhecimento da independência do enclave, almejado desde o primeiro momento em que se iniciaram as negociações - ainda que infrutíferas - com o governo português.

A bem da verdade, Cabinda organizou, desde o início da guerra colonial pela independência, seus próprios movimentos emancipatórios, aglutinados em torno da Frente pela Libertação do Enclave de Cabinda (FLEC), no ano de 1963, ainda sob o domínio colonial português.

Falando-se em domínio colonial português, é importante destacar que, segundo os documentos dos próprios portugueses, e do Tratado de Simulambuco, assinado entre autoridades portuguesas e representantes dos povos de Cabinda, no contexto da Conferência de Berlim, Angola e Cabinda constituíam possessões portuguesas diferentes em território africano, sendo o primeiro uma colônia portuguesa, e a segunda um protetorado do mesmo país, e que, para todos os efeitos, Cabinda não era Angola, ainda que em certos documentos assim apareça referida, mas apenas com objetivos administrativos.

[...] no que concerne à nação portuguesa, sempre constou que o território de Portugal era, na África Ocidental, constituído pelos 
arquipélagos de Cabo Verde, de São Tomé e Príncipe, Forte de S. João Baptista da Ajuda, Guiné, Cabinda e Angola.

Registre-se e recorde-se, que até meados do século passado, por exemplo, quem viajasse de avião ou navio e que desembarcasse em Cabinda passava por uma alfândega autónoma, o que só é entendível à luz de serem dois territórios distintos como defendem os autonómicos. Isto, apesar de, em 1955, para facilitar a administração do território de Cabinda ter sido considerado como um distrito de Angola. Embora reconhecendo que de facto se tratava de um mero expediente administrativo, Portugal reafirmava que Cabinda não era Angola. (ALMEIDA, 2013, p. 78, grifos nossos)

Esse mesmo governo português que afirmava a independência entre os territórios de Cabinda e Angola, nos tratados de paz assinados em 1974 e 1975, e ao longo do governo de transição, não se envolveu na questão do povo cabinda, nem sequer houve representantes do enclave ao longo das negociações, e muito menos no governo de transição, a despeito das reivindicações feitas pelos movimentos de libertação de Cabinda aos representantes do governo português.

A situação em Angola vinha a deteriorar-se progressivamente desde que em Alvor, os três únicos e reconhecidos representantes nacionalistas de Angola assinaram o acordo que reconheceria a independência de 
Angola, de Cabinda ao Cunene, a 11 de Novembro de 1975. Nesta reunião, apesar de terem participado, oficiosamente, alguns régulos e sobas angolanos, não houve qualquer representação oficial, nem oficiosa, de personalidades cabindenses. [...]

Esta atitude de Portugal, enquanto potência, foi mal recebida pelos dirigentes autonómicos de Cabinda, que levaram a FLEC a autoproclamar a independência, em 1 de Agosto de 1975, e a iniciar as suas actividades armadas a 8 de Novembro deste mesmo ano. [...] A desilusão com Portugal, sobretudo a partir de 1974, pode ser resumida na afirmação de Agostinho Chicaia, presidente da extinta Mpalabanda, Associação cívica de Cabinda: "Não vamos mais contar com Portugal. O Governo português tem interesses muito fortes em Cabinda, particularmente em Angola, e vai ser difícil pronunciar-se sobre uma eventual solução a favor do povo de Cabinda, porque o lado económico sempre fala mais alto". (ALMEIDA, 2013, p. 83)

A partir dessa autoproclamação de independência, iniciouse uma espécie de guerra civil de guerrilhas no território de Cabinda, que acabou vitimando milhares de inocentes pegos no meio do fogo cruzado, dentre os quais encontramos Ngo Nuni, cuja infância relatada em $O$ dia em que não voltei a casa se dá justamente durante esse período de conflitos - ainda não resolvidos, posto que o governo angolano ainda não reconhece a independência de Cabinda. 


\section{"Uma infância atribulada num cenário de guerra"}

Tendo apresentado alguns conceitos de "Infância", "Experiência" e "Memória" com os quais trabalharemos, e trazido algumas informações acerca do contexto histórico no qual se passa a narrativa da obra em estudo, podemos dar início à análise propriamente dita de alguns dos eventos de infância relatados em $O$ dia em que não voltei a casa.

Destacamos, porém, que devido aos limites possíveis em um artigo, não poderemos nos aprofundar sobre cada um dos episódios contados pelo autor, e por isso escolhemos alguns deles, que consideramos de maior relevância para o estudo da infância de Ngo Nuni no contexto da guerra de libertação de Cabinda.

A primeira data à qual se refere Ngo Nuni é a de 1977, quando então contava com cinco anos de idade, e a partir daí podemos presumir que a maioria dos episódios descritos na obra, no que se refere à infância do autor, se passam ou nos anos finais da década de 1970, ou ao longo da década de 1980. Sabendo disso, como uma informação histórica complementar, julgamos importante apresentar o contexto específico desse período no que diz respeito à Cabinda. A esse respeito nos informa Almeida.

Politicamente, os dirigentes de Cabinda não se conseguem unir para fazer valer a sua 
voz, quer junto da comunidade internacional quer, e principalmente, junto do Governo de Angola, aquele que deveria ser seu principal interlocutor, desde o momento em que Portugal abdicou das suas responsabilidades históricas, já anteriormente referidas. No caso da FLEC esta é representada por várias facções que se digladiam entre si. [...] Durante algum tempo coexistiram a FLECRanque Franque [...] a FLEC-N'Zita, [...] e a FLEC-Lubota [...] ao mesmo tempo que, em Novembro de 1977, emerge o Comando Militar para a Libertação de Cabinda, e em Junho de 1979 aparecem, formalmente e em nome de um Movimento Popular de Libertação de Cabinda (MPLC), as Forças Armadas de Libertação de Cabinda. [...] Contudo a posição da FLEC - ou das diferentes FLEC - no enclave de Cabinda teria, na década de 80 , um apoio que tinha tanto de imprevisível como de surpreendente. A UNITA, com o auxílio do então Zaire, de Mobutu, dava a sua cooperação militar no combate ao MPLA, tentando fechar o cerco militar às então FAPLA (Forças Armadas Populares de Libertação de Angola) e aos paramilitares cubanos. O MPLA tinha cerca de 15 mil militares bem armados e apoiados por forças motorizadas e aéreas em Cabinda. (ALMEIDA, 2013, p. 84)

O primeiro dos episódios que selecionamos se encontra logo nas primeiras páginas do livro, e ilustra de forma bastante direta - também chocante e surpreendente - os conceitos de "Experiência" e "Memória" acima 
apresentados. É um trecho relativamente longo, acerca da presença dos militares angolanos e cubanos nas vilas civis de Cabinda, mas que merece ser lido com atenção.

Em 1977, com cinco anos de idade, mal conhecia ainda o que era a vida e me vi obrigado a aprender a sobreviver. $\mathrm{Na}$ pequena aldeia onde vivia com meus pais, um pequeno vilarejo de menos de vinte famílias, onde aprendi a dar os meus primeiros passos antes de aprender a brincar, já havia necessidade de aprender como escapar em caso de invasão militar que sempre esteve iminente. Cabinda já estava em guerra e nem as crianças eram poupadas.

A infância não merecia qualquer tipo de respeito e muito menos era certificado de imunidade ou prova de inocência por parte dos militares angolanos que, nesse momento da história, usavam o pânico e o terror como instrumentos de persuasão e submissão das populações às arbitrariedades do poder então instituído. Tiroteios e todo tipo de sons de armas, leves e pesadas, assombravam o nosso cotidiano a qualquer momento do dia ou de noite.

Eu tinha pavor do uniforme militar, porque me parecia a ilustração do Inferno. Militares armados até os dentes quase sempre se faziam presentes por toda parte intimidando todos. Nem os animais escapavam à demonstração da autoridade e força dos militares angolanos. Cachorros eram abatidos se ousassem latir com a presença dos homens de farda. Por mais que até então não tivesse a noção exata das mazelas da vida em tempos de conflitos, como 
naquele momento, a ameaça que os FAPLA (Forças Armadas pata Libertação de Angola), representavam contra tudo e todos, essa, nenhuma criança, por mais inocente que fosse, podia ignorar. (NUNI, 2020, p. 19)

Como podemos observar claramente, o cenário de guerra entre as forças de libertação de Cabinda e as tropas angolanas deixava suas marcas na sociedade civil, inclusive em uma aldeia, claramente desmilitarizada, onde os militares de Angola exerciam seu poder de forma tão intensa e brutal que, de acordo com as palavras de Ngo Nuni, nem mesmo as crianças e os animais eram poupados dos atos de violência.

Devemos lembrar que, quando ocorrem os eventos descritos na citação, o autor da narrativa contava com apenas cinco anos de idade, e hoje, passados cerca de quarenta e quatro anos, ele ainda é capaz de nos descrever com precisão os sentimentos que sentia em relação às tropas angolanas, e do medo que sua presença constante causava nos moradores de seu vilarejo, chegando-se ao ponto em que eram elas - na cabeça de uma criança de cinco anos, reforçamos - a própria imagem do inferno.

Consideramos bastante intensa a descrição de que o autor, e presumivelmente as demais crianças de sua aldeia, desde a mais tenra idade terem que aprender a defender-se de bombardeios e invasões, "antes mesmo de aprenderem 
a brincar". Pensando nisso, não podemos deixar de nos remeter ao pensamento de Benjamin, segundo o qual a vivência em um cenário de guerra não deixava seus partícipes mais ricos em experiências, posto que os horrores vivenciados não poderiam ser comunicados "de boca a boca".

É igualmente importante destacar que, na narrativa que Ngo Nuni desenvolve em sua obra, as experiências traumáticas da vivência de uma guerra civil poderiam ser consideradas ainda menos comunicáveis de boca a boca, posto que sofridas por uma criança, cuja compreensão - como o próprio autor nos informa no trecho acima reproduzido - dos acontecimentos todos que os rodeavam, à época, era bastante limitada, muito em decorrência da idade, mas que mesmo assim, qualquer criança, por mais inocente que fosse, era capaz de compreender a ameaça que pesava sempre em suas cabeças, a ponto de ser guardada em suas memórias com clareza mesmo após passadas mais de quatro décadas de sua ocorrência.

Avançando na leitura de $O$ dia em que não voltei a casa, somos informados que os membros da aldeia são obrigados a refugiarem-se na floresta, sob proteção da FLEC, diante de uma iminente invasão do vilarejo pelos soldados angolanos. 
A partir desse refúgio improvisado na floresta, decidiram os líderes das famílias a procurarem abrigo seguro além das fronteiras, no então Zaire, sendo escoltados no trajeto por soldados da mesma FLEC.

Isso nos remete ao segundo trecho destacado para nosso estudo, que se refere ao final da viagem de travessia - através das florestas cabindas - das famílias da aldeia de Ngo Nuni para o Zaire, quando são abordados na fronteira por soldados do país vizinho que, mesmo nominalmente apoiadores da causa cabinda, e cientes da situação de vulnerabilidade em que se encontravam os refugiados, não hesitam em exercer seu poder sobre eles, ainda que em grau menos violento, porém igualmente traumático. Assim Ngo Nuni nos descreve os fatos:

Ao chegar a centenas de metros perto da fronteira, a nossa escolta nos reuniu pela última vez para nos informar que a partir dali não nos acompanhariam mais, visto que do outro lado da fronteira era o território zairense; seria, então, a vez dos policiais locais a tomarem conta de nós e que nos orientariam por onde iríamos, e que tudo correria sem incidentes. Para quem já vivia há meses em situações bastante atípicas, não havia receio para surpresas mais desagradáveis do que a realidade que tínhamos deixado para trás. Eu caminhava de mãos dadas com o meu pai, e o resto da família vinha logo em seguida. Ao chegar na 
fronteira, os policiais zairenses abriram uma barreira improvisada. Um deles logo veio em nossa direção e pediu que meu pai colocasse no chão a mala que carregava sobre a cabeça para que fôssemos revistados.

Assim que colocou a mala no chão, o próprio policial a abriu e pôs-se a vasculhar o conteúdo. Não tardou em pegar um par de sapatos do meu pai e disse com toda tranquilidade e com um sorriso de deboche que aqueles sapatos certamente serviriam para ele. $O$ meu pai entendeu bem as palavras e ficou preocupado porque se o policial realmente estivesse falando sério, não só perderia os sapatos. Ainda havia algo dentro dos sapatos muito mais importante para o meu pai. Ali estava meu pai, paralisado, sem saber como reagir, porque dentro dos sapatos estava todo dinheiro que seria para o sustento da família num país que nos era ainda desconhecido.

Como gesto de desespero, tentou colocar a mão dentro dos sapatos para tirar o dinheiro, mas o policial disse que não era necessário, porque ele também gostava dos Kwanzas (moeda angolana). [...]

Nós estávamos numa situação que hoje eu definiria de extrema fragilidade, fugindo, deixando para trás tudo o que meus pais haviam conquistado durante anos de trabalho. Os policiais zairenses que estavam nos recebendo eram seres humanos que compreendiam bem a nossa situação e, mesmo assim, sem qualquer tipo de remorso, tiravam tudo que podiam dos refugiados. Meu pai, nesse momento, nem sabia aonde seria o nosso destino final, mas uma certeza ele tinha. Não tinha nenhum tostão 
para qualquer eventualidade. Ele estava visivelmente abatido, com um semblante desesperado. (NUNI, 2020, p. 40-41)

O terceiro episódio que escolhemos como recorte para o presente artigo ocorre já passados alguns meses do estabelecimento no Zaire, quando o narrador se encontra em um campo de refugiados diferente do primeiro que os recebeu, vivendo com seu irmão mais velho, enquanto seus pais ainda não haviam podido também se mudar.

Esse terceiro episódio diz respeito à vida escolar, ou mais precisamente, a certos momentos da vida escolar do autor na escola do campo de refugiados, onde não deixou também de sofrer violências, mesmo acreditando estar em um local teoricamente protegido.

Nesse caso em especial, a violência é perpetrada por duas de suas colegas de turma que, muito provavelmente em decorrência da observação de atitudes semelhantes tomadas pelos adultos - como as descritas na citação anterior, e outra tantas narradas no decorre da obra roubam o lanche do autor, e o agridem fisicamente por tentar opor-se à essa atitude, exatamente como os soldados angolanos e vários dos policiais zairenses faziam com quem ousasse desafiá-los ou discordar de suas ordens. Mesmo não intencionalmente, podemos observar que esses 
adultos violentos estavam transferindo, pelo expediente do mau-exemplo, experiências aos mais jovens, tornando-os também violentos.

Na minha primeira semana de aulas em Kimbianga, ele [irmão do autor] fazia questão de me acompanhar até a escola e, à tardinha, ainda me buscar. Assim fê-lo até eu resolver pedir que me deixasse ir sozinho, porque quase todos os meninos da minha idade faziam o mesmo. Nunca esqueci a primeira vez que ele me deixou ir sozinho. Eu cumpri todo o ritual como era de costume. Fiquei na fila da turma no pátio, cantei junto com os coleguinhas e fui até a sala de aula, sentindome, de certa forma, independente.

Ao longo do recreio, como todos os alunos faziam todos os dias, cada um tirava o seu lanche e comia sem incidentes, até então. Naquele dia, nem tudo estava certo. [...] Uma menina mal-humorada me pediu que the desse o meu lanche. Ela não parecia depender da minha colaboração para lançar mão no que queria. Mesmo assim, não acreditei em tamanho atrevimento, já que ela tinha a sua própria comida. 0 pouco tempo que eu hesitei para atender ao pedido foi o suficiente para que a sua amiga se irritasse e, sem se dar ao trabalho de me pedir, aquela impaciente e petulante menina arrancou com força tudo o que eu tinha levado. $E$, ao tentar defender a minha refeição, ainda acabei apanhando das duas, com todos os coleguinhas em volta olhando para mim. Nesse dia, chorei pensando nos meus pais. (NUNI, 2020, p. 81) 
O quarto episódio que selecionamos também diz respeito a uma experiência aprendida pela observação, dessa vez pelo próprio autor, e que se refere à questão da própria sobrevivência, e da luta pelos seus objetivos.

Ao longo da obra, Ngo Nuni nos informa acerca de seu desejo de estudar, de concluir os estudos e avançar neles, o que, em um contexto de guerra e na situação de refugiado não é algo simples, e pode mesmo chegar a ser um sonho impossível, em decorrência de inúmeros empecilhos que se apresentam ao pretenso estudante, dentre os quais, a ameaça pesada e constante da fome, que poderia agir como um grande impedimento para a continuidade dos estudos de um jovem refugiado, como ocorre com um dos irmãos do autor, segundo ele nos informa em seu texto.

Tendo esse sonho, e observando o que ocorrera com seu irmão, Ngo Nuni decide - já deixando a infância propriamente dita, e entrando na adolescência - preparar-se para essa terrível ameaça, a fim de que, quando ela chegasse - e ele tinha a mais absoluta certeza que em algum momento de fato chegaria, ela não pudesse ser suficiente para impedi-lo de realizar seus sonhos.

Em determinado momento, pedi à minha mãe para que diminuísse a quantidade de comida em relação ao que eu consumia 
habitualmente. Por alguns dias ela fez isso sem questionar. Eu comia e continuava o meu dia a dia normal, como se não houvesse nada de atípico. Mas, passado algum tempo, a minha mãe achou estranho o fato de eu comer menos do que ela achava normal e resolveu perguntar o que estaria por detrás da mudança. Disse-lhe a verdade, que estava me preparando para um momento em que certamente teria de passar fome longe dela e do meu pai e que, quanto mais cedo eu me treinasse para isso, provavelmente as dificuldades seriam mínimas.

Enquanto eu defendia a minha teoria, a minha mãe olhava para mim chorando, mas consciente de que tinha alguma razão no que eu estava lhe dizendo, e que nada ela poderia fazer para me impedir de continuar com a prática que adotei como exercício de preparação. Não apenas achei pertinente a necessidade daquela preparação para mim, mas, como também tinha uma convicção quase absoluta de que o tempo de vacas magras era realmente inevitável e que de maneira alguma poderia justificar uma desistência ou fuga à vida de estudante, longe dos meus pais, por causa da fome, como aliás havia acontecido com o Tibúrcio, um dos meus irmãos. (NUNI, 2020, p. 97)

Por último, escolhemos um trecho da obra $O$ dia em que não voltei à casa que não se refere à infância do autor propriamente dita, mas já à sua adolescência, haja vista que contava ele então com dezesseis anos, e fazia uma visita ao seu país natal, na casa de uma irmã mais velha, onde 
ainda era evidente a violência que as tropas de ocupação de Angola exerciam sobre o povo civil, que contava com praticamente nulas possibilidades de defesa.

Durante os trinta dias que lá estivemos, vestíamos, falávamos e nos comportávamos como zairenses, para que fossemos confundidos, porque eles, embora não serem bem vistos pelos angolanos naquele momento, pelo menos não eram alvos de busca para o serviço militar obrigatório, como eram os jovens cabindeses, que não tinham a liberdade de circulação na sua própria terra, caçados como animais. Não só nos fantasiávamos de zairenses, como também falávamos kikongo e Lingala que são as línguas nacionais do Zaire, das quais já tínhamos algum domínio. Apesar daquelas precauções todas, um dia, por distração, fui pego por militares que estavam rusgando. Uma vizinha da minha irmã Nenete viu a cena e imediatamente foi informa-la dobre o que estava acontecendo. A minha irmã correu, desesperada, para tentar me defender. Implorou humildemente para aqueles monstros desprovidos de qualquer sentimento humano para que me libertassem. O militar que me havia capturado disse a Nenete que o pedido dela só seria atendido em troca de um beijo.

- Mas como vou te dar um beijo se sou uma mulher casada?

- replicou minha irmã.

- Eu não disse que o beijo é na boca.

- retrucou aquele militar imundo e malcheiroso. 
A Nenete concordou em dar o beijo, desde que o militar, antes disso, me deixasse seguir para casa. Assim fez o meu carrasco.

Foi uma desagradável situação. A minha irmã, depois de me salvar do infortúnio, voltou feliz para casa, mas eu não gostei nem um pouco de ela ter passado por aquela deplorável situação por minha causa. (NUNI, 2020, p. 108-109)

\section{Considerações finais}

O presente artigo teve como objetivo central articular os conceitos de "Infância", "Experiência" e "Memória" em relação à obra $O$ dia em que não voltei à casa, de Ngo Nuni, publicada no ano de 2020, e que traz relatos em primeira pessoa das vivências do autor em um contexto de guerra, durante sua infância no enclave de Cabinda, que desde antes da própria independência angolana em relação à Portugal, busca uma própria emancipação de seu território em relação à própria Angola.

Iniciamos nosso texto apresentando os conceitos com os quais trabalhamos ao longo do seu desenvolvimento, acerca das ideias de "Infância", conforme Ariès e Postman; de "Experiência", conforme Benjamin; e de "Memória", conforme Gagnebin, e pudemos observar que a infância idade da vida construída socialmente a partir do século XVI pode ser considerada como o período em que o ser humano 
mais adquire experiências, através dos ensinamentos dos mais velhos, e da convivência com eles, ao mesmo tempo em que constatamos que eventos traumáticos tornam aqueles que os vivenciam mais pobres de experiências comunicáveis verbalmente, mas não através de textos.

É nesse ponto que entra a questão da "Memória", acionada justamente para transmitir - no caso dos livros de guerra mencionados por Benjamin, e no do livro $O$ dia em que não voltei à casa, de Ngo Nuni - essas experiências não comunicáveis de boca a boca, mas cuja transmissão é de fundamental necessidade, seja para evitar que ocorram novamente, como no caso dos livros de guerras, seja para denunciar crimes e atrocidades cometidas contra um determinado povo, cujo único "crime" é desejar a própria independência, e uma vida pacífica, como é o caso do livro estudado no presente artigo.

A partir desses conceitos - e apresentando um breve panorama do contexto histórico da obra em estudo - partimos para a observação de alguns episódios descritos pelo autor de $O$ dia em que não voltei a casa, que exemplificam de forma intensa e completa as ideias de experiências traumáticas obtidas através de suas vivências, e que, apesar de não facilmente comunicáveis, 
necessitam serem transmitidas, como um ato de denúncia contra os verdadeiros crimes selvagens cometidos contra o povo de Cabinda.

Assim é a obra de Ngo Nuni, um livro de memórias muito vívidas e claras de suas experiências traumáticas na infância - que denuncia as atrocidades cometidas contra o povo civil de Cabinda, tanto pelos soldados angolanos de ocupação, como por aqueles que supostamente deveriam defendê-los, como alguns dos policiais zairenses, como o que mencionamos em um dos recortes estudados.

Por fim, gostaríamos de terminar o presente artigo com uma última citação, na qual o autor resume, com palavras diretas, a situação de sua infância no contexto da guerra de libertação do enclave de Cabinda, e de sua vida no exílio no Zaire. Assim nos fala Ngo Nuni:

$\mathrm{Na}$ condição de refugiados, havíamos aprendido muita coisa com as próprias experiências vividas, sobre adversidades que a nossa condição nos impunha. Não tínhamos muito tempo para ficarmos anestesiados com decepções, porque a nossa trajetória já era cercada por várias. (NUNI, 2020, p. 98)

\section{Referências}

AGAMBEN. Giorgio. Infância e história. Destruição da experiência e origem da história. Tradução de Henrique Burigo. Belo Horizonte: Editora UFMG, 2005. 
ALMEIDA, Eugênio Costa. O difícil processo de definição de fronteiras e pertenças político-identitárias no debate de Cabinda. Cadernos de Estudos Africanos, Lisboa: Centro de Estudos Africanos da Universidade de Lisboa, n. 25, p. 65-93, junho de 2013.

ARIÈS, Philippe. História social da criança e da família. Tradução de Dora Flaksman. Rio de Janeiro: Guanabara, 1986.

BENJAMIN, Walter. Experiência e pobreza. In: BENJAMIN, Walter. Obras escolhidas I. Magia e técnica, arte e política. Ensaios sobre literatura e história da cultura. Tradução de Paulo Sérgio Rouanet. São Paulo: Brasiliense, 2021.

GAGNEBIN. Jeanne-Marie. Verdade e memória do passado. In: GAGNEBIN. Jeanne-Mari. Lembrar escrever esquecer. São Paulo: Editora 34, 2009. HERNANDEZ, Leila Leite. A África na sala de aula. Visita à história contemporânea. São Paulo: Selo Negro, 2008.

NUNI. Ngo. O dia em que não voltei a casa. Uma infância atribulada num cenário de guerra. São Paulo: Anjo, 2020.

POSTMAN, Neil. O desaparecimento da infância. Tradução de Suzana Menescal de Alencar Carvalho e José Laurenio de Melo. Rio de Janeiro: Graphia, 1999.

\section{Diana Navas.}

Pós-doutora pela Universidade de Aveiro (Portugal).

Atua como coordenadora e professora do Programa de Estudos PósGraduados em Literatura e Crítica Literária da PUC-SP.

É vice-líder do Grupo de Pesquisa "Crítica Literária: tendências e perspectivas" (PUC-SP/CNPQ) e membro do Grupo de Pesquisa "A narrativa ficcional para crianças e jovens: teorias e práticas" (UERJCNPQ) e do GT da Anpoll "Leitura e Literatura Infantil e Juvenil".

E-mail:diana.navas@hotmail.com/dnavas@pucsp.br

Lattes: https://lattes.cnpq.br/9770050223986051

ORCID iD: http://orcid.org/0000-0002-4516-5832

\section{Evandro Fantoni Rodrigues Alves}

Doutorando em Literatura e Crítica Literária pela Pontifícia Universidade Católica de São Paulo (PUC/SP). 
Atua como Professor Efetivo de História na Rede Municipal de Educação Básica de São Paulo.

Participa dos Grupos de Pesquisa em Crítica Literária (PUC/SP), e TAPHOS (USP); e dos Grupos de Estudo em Literatura e Ditaduras (PUC/ $S P)$, e Escrita Criativa (PUC/SP).

E-mail: evandro.fantoni.ra@gmail.com

Lattes: https://lattes.cnpq.br/8404223798107944 